\title{
NOVOS ESTUDOS DO LETRAMENTO E ANÁLISE DA CONVERSA: O AJUSTE AO INTERLOCUTOR EM PRÁTICAS DE LETRAMENTO EM SAÚDE
}

\section{NEW LITERACY STUDIES AND CONVERSATION ANALYSIS: RECIPIENT DESIGN IN HEALTH LITERACY PRACTICES}

Ana Cristina Ostermann $(\mathrm{CNPq})$ Universidade do Vale do Rio dos Sinos, Porto Alegre, Rio Grande do Sul, Brasil

Roberto Perobelli Universidade Federal do Espírito Santo, Vitória, Espírito Santo, Brasil

Resumo: Este artigo propõe a relação entre um dos princípios fundamentais da interações humanas e caro à Análise da Conversa (AC), o princípio do ajuste ao/à interlocutor/a, e algumas das características centrais nos Novos Estudos do Letramento (NLS). De forma a elucidar a relação aqui proposta, analisamos atendimentos em saúde em que o profissional de saúde produz explicações a suas pacientes por meio de uma multiplicidade de recursos e da criação e atribuição de sentidos "sob medida" para cada paciente. As análises evidenciam que, ao fazer ajustes de diferentes naturezas às diferentes interlocutoras, o profissional leva em conta os "letramentos em saúde" de cada interagente e oportuniza que o evento consulta seja, também, um evento de letramento. Por fim, a partir da análise minuciosa dos dados, proporcionada pela perspectiva teórico-metodológica da AC, associada aos entendimentos propostos pelos Novos Estudos de Letramento, faz-se uma reflexão sobre Letramento em Saúde, conceito esse amplamente utilizado em países como EUA, Reino Unido e Holanda, e sua relevância para a missão da educação de assegurar uma participação social plena e equitativa a cada cidadão/cidadã.

Palavras-chave: Letramento em Saúde; Novos Estudos do Letramento; Análise da Conversa; Ajuste ao/à interlocutor/a

Abstract: This article proposes an association between the principle of recipient design - a principle of human interaction and of fundamental importance to Conversation Analysis (CA), and some of the ideas that guide the New Literacy Studies (NLS). The interactional principle of recipient design becomes salient and relevant to NLS as it focuses precisely on the resources that interactants rely on in order to produce talk that is both context-sensitive and particularized to each interlocutor. Our analysis, that centers around medical consultations, demonstrates how physicians make use of a range of semiotic resources to adjust their talk to different interlocutors. The analysis shows that they do so by orienting to what their interlocutor displays in each new turn at talk not only concerning his/her understanding of what came before, but also on his/her level of health literacy which, in its turn, relates to his/her social, educational, cultural, and linguistic background. In addition to claiming that the principle of recipient design can (and perhaps should) be associated with and incorporated by the New Literacy Studies, we also sustain the relevance of further research that looks into that association and the possible 
practical advancements it can generate towards the promotion of more equitable citizens' social participation.

Keywords: Health Literacy; New Literacy Studies; Conversation Analysis; Recipient Design

\section{INTRODUÇÃO ${ }^{1}$}

É quinta-feira de manhã, junho, em uma instituição de ensino superior. A paciente professora e pesquisadora, apresentando dificuldade na produção de fala em função de uma laringite, procura o médico do trabalho em busca de tratamento. Reproduzimos o início dessa interação, após a troca inicial de cumprimentos:

Interação 1: "Veja bem os prefixos" (reproduzida a partir da memória da paciente) ${ }^{2}$

$\begin{array}{ll}01 \text { MÉD: } & \text { Como posso ajudá-la? } \\ 02 \text { PAC: } & \begin{array}{l}\text { ((apresentando dificuldades na produção } \\ \text { de fonemas sonoros)) Pois então. Eu tô bem, }\end{array} \\ 03 & \text { mas eu tô afônica e preciso dar aula. } \\ 05 \text { MÉD: } & \text { Não. A senhora não está afônica. } \\ 06 & \text { A senhora está disfônica. } \\ 07 \text { PAC: } & \text { Ah, sim. Eu sei. Eu sou linguista. } \\ 08 \text { MÉD: } & \text { Veja bem os prefixos. } \\ \text { 09 PAC: } & \text { Sim. Sim. Eu entendo. } \\ \text { 10 MÉD: } & \text { A é sem. Ausente. DIS é em mau estado. } \\ 11 \text { PAC: } & \text { Sim. Eu sei. } \\ \text { 12 MÉD: } & \text { A senhora ainda consegue produzir voz, não é? } \\ \text { 13 PAC: } & \text { ((assente com a cabeça)) } \\ 14 \text { MÉD: } & \text { Então. A senhora está DISfônica. Não Âfonica. } \\ 15 \text { PAC: } & \text { Pois é. O que eu queria, então, } \\ 16 & \text { é recuperar minha voz pra poder dar minhas aulas. }\end{array}$

Fonte: Os autores.

O que acontece nessa interação, para além de um típico caso de mansplaining - ou, aqui, docsplaining -, é o que se chama (na Análise da Conversa) de fala "não ajustada ao/à interlocutor/a"3. O médico, a partir da linha 5, suspende a relevância sequencial de iniciar a atividade de anamnese após a apresentação da queixa principal da paciente (linhas 2-4) para corrigir como ela se refere a seu sintoma (linhas 5-6) e ensinar morfologia a uma paciente que se autorrevela como linguista na própria interação (linha 7) e que afirmara (linha 7) e reafirmara

\footnotetext{
${ }^{1}$ Agradecemos ao Conselho Nacional de Desenvolvimento Científico e Tecnológico (CNPq) pelo apoio obtido em diferentes etapas do desenvolvimento da pesquisa maior de onde advém este artigo, por meio de Bolsa de Produtividade em Pesquisa (Processo no 309351/2016-2) e auxílio à pesquisa da Chamada Universal 01/2016 (Processo no 409894/2016-8), concedidos à primeira autora.

2 Tratamos esse fragmento como "Interação", por sua representação se dar a partir da memória da paciente. Diferentemente das demais transcrições ao longo deste artigo, todas transcritas a partir de registro em áudio, e que serão denominadas "Excertos", esse fragmento também não recorre às convenções de transcrição propostas por Gail Jefferson (1984).

${ }^{3}$ Cf. próxima seção deste artigo.
} 
(linha 9) compreender os significados dos prefixos em questão. ${ }^{4}$ Em suma, o médico não ajusta sua fala à interlocutora em questão - nem suspende o curso de ação em que embarca (i.e. discorrer sobre sufixos), mesmo após ser informado pela paciente sobre a dispensabilidade desse curso de ação.

Adentramos agora outro contexto, também na área da saúde. Trata-se de uma consulta ginecológica, num posto especializado em saúde da mulher do Sistema Único de Saúde (SUS). A paciente, que fizera recentemente coleta de material do colo uterino, fora encaminhada para exame em consultório em função de ter sido constatada a presença de cistos de Naboth. $\mathrm{O}$ Excerto 1 acontece logo após o exame físico.

Excerto 1: "O orificio de saída, o buraquinho por onde sai" (POSTO0405046GMelissa)

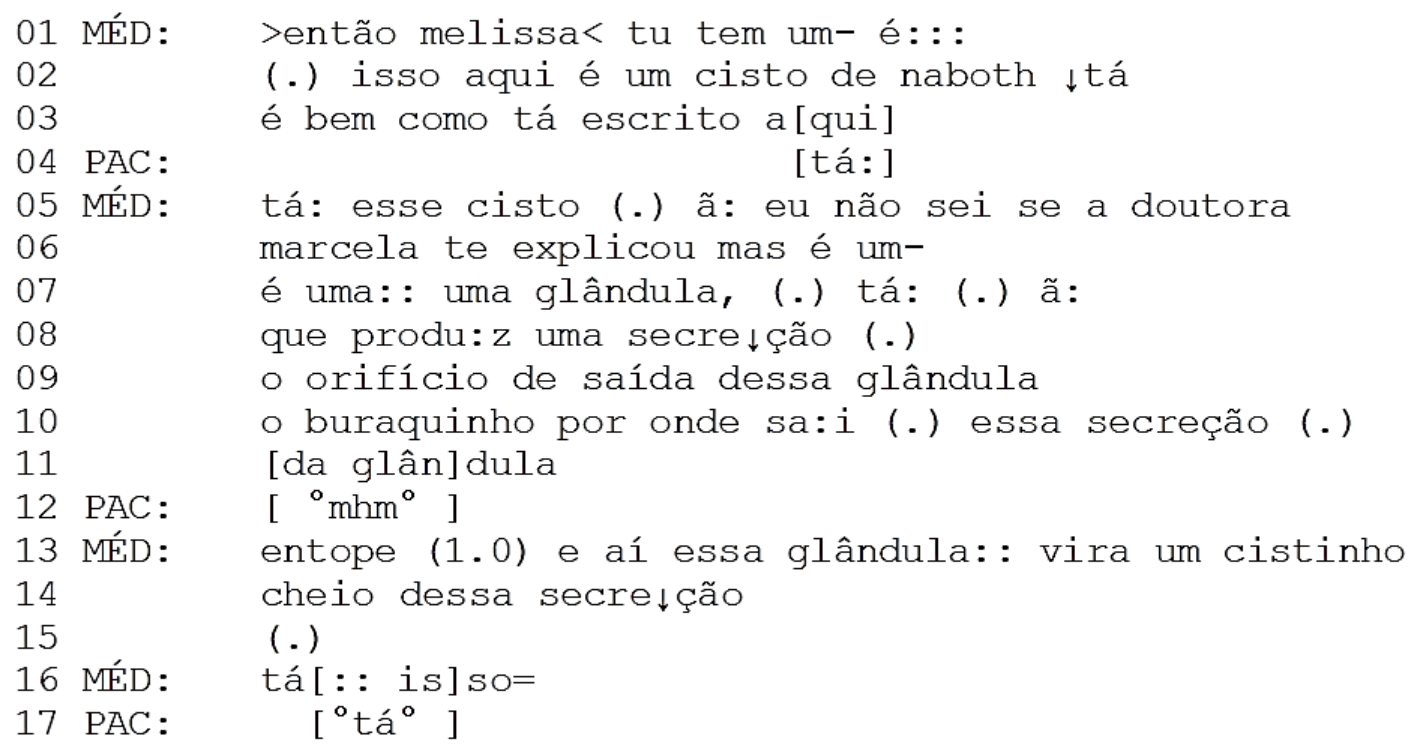

Fonte: Os autores

Observe-se, em especial, as linhas 5 a 11. Após confirmar o que a médica anterior constatara, i.e. cistos de Naboth, o médico (que chamamos aqui de Gabriel) inicia seu turno com o que se projeta sintaticamente ser uma explicação em construção ("tá: esse cisto", linha 5). A projeção de uma explicação (em construção) é suspensa para fazer outra ação antes: calibrar a explicação em relação ao que a paciente pode já saber ou ter sido informada ("ã : eu não sei se a doutora marcela te explicou", linhas 5-6), como mostra a Fig. 1.

\footnotetext{
${ }^{4}$ Há que se pontuar aqui que a própria descrição da paciente sobre o seu sintoma (i.e. afonia), por sua vez, é aquela usada na fala cotidiana. Quem, afinal de contas, na vida cotidiana (como ao chegar numa farmácia e pedir pastilhas para a garganta), pediria algo como: "Me vê aí, por favor, uma pastilha para disfonia?"
} 
Figura 1: Suspensão de uma ação (i.e. explicar o que é cisto) para realizar outra ação (i.e. especular se a Dra. Marcela já explicara)

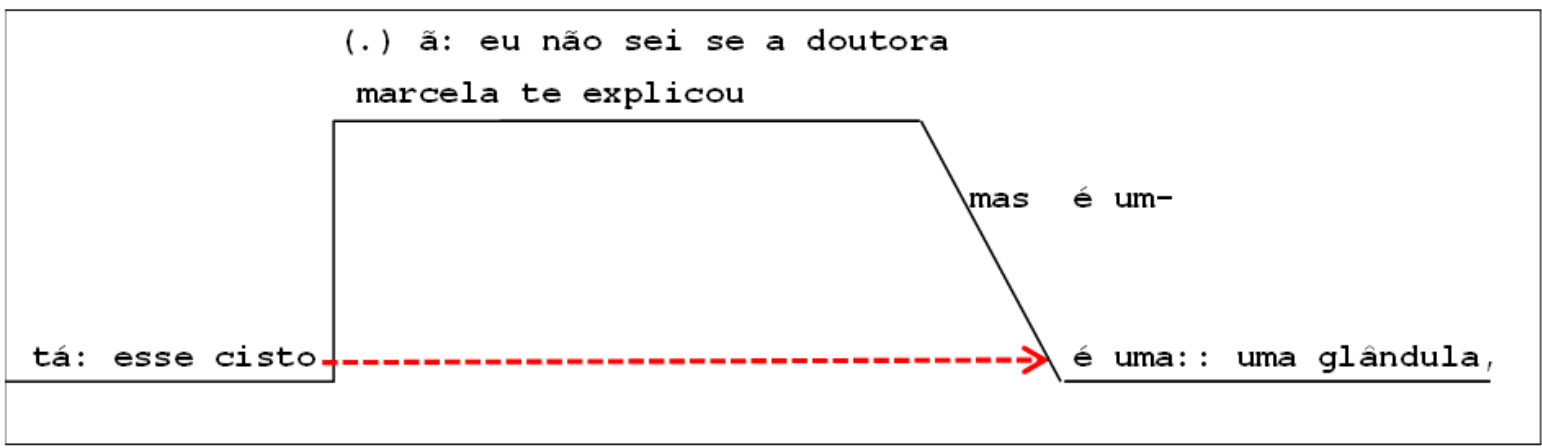

Fonte: Os autores.

Veja-se que o médico Gabriel marca a suspensão da atividade em andamento com uma pausa, seguida de hesitação (“ ( . ) ã :", linha 5) para primeiramente se informar sobre o que a paciente já sabe (linhas 5-6), i.e. alcançar o "acesso epistêmico" (STIVERS et al., 2011) da paciente.

Observe-se ainda o que o médico faz na continuidade desse mesmo turno (Fig. 2). Assim que produz o sintagma nominal "o orifício de saída dessa glândula” (linha 9), ele realiza um autorreparo ${ }^{6}$ (DREW et al., 2013), suspendendo o fluxo da produção de seu próprio turno, para substituir esse sintagma por outro: "o buraquinho por onde sa: $i$ (.) essa secreção (.)" (linha 10).

Figura 2: Suspensão de uma ação (i.e. explicar o entupimento da glândula) para realizar outra ação (i.e. explicar o que é orifício)

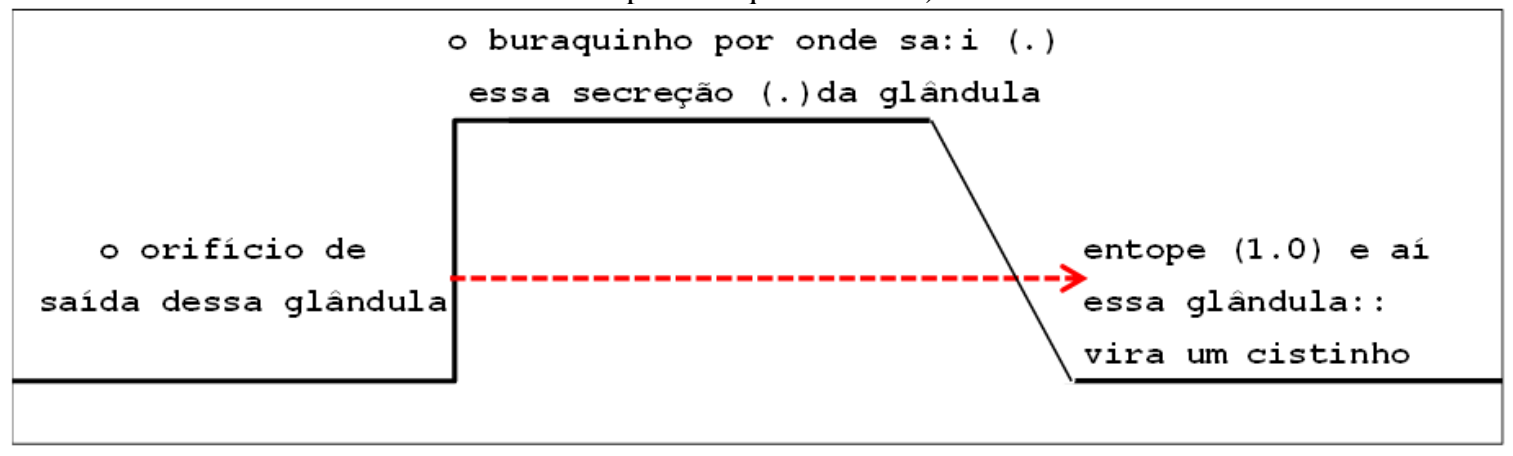

Fonte: Os autores.

Em dois momentos distintos - ao referir-se ao que a outra médica poderia já ter informado à paciente e ao substituir um sintagma em registro técnico para algo mais universalmente acessível, ações essas que demandam poucos segundos da interação -, o médico realiza importantes ajustes ao saber da paciente.

\footnotetext{
${ }^{5}$ Observe-se que para acontecer um ajuste adequado da fala é necessário que o falante corrente tenha acesso ao quanto o interlocutor já sabe sobre X, de forma a calibrar sua fala para não ser redundante (explicar o que o outro já sabe) ou, alternativamente, assumir como dado e compreendido algo que o outro ainda não sabia (e, com isso, pressupor demais).

${ }^{6}$ Autorreparo é um tipo de reparo, mecanismo comum nos mais variados eventos de fala-em-interação, usado pelos participantes para lidar com problemas de articulação na fala ou de escuta ou de entendimento. No autorreparo, o participante que inicia um turno, configurado na interação como turno-fonte de problema, apresenta, ele mesmo, uma "solução" para esse problema. Característicos autorreparos são as substituições que falantes fazem de um item lexical por outro (SCHEGLOFF et al., 1977).
} 
Como analistas da conversa que entendem transdisciplinaridade como uma construção paradigmática que propõe uma integração multidimensional e multirreferencial (cf. SOUZA; PINHO, 2017, p. 99) entre as disciplinas, é por meio do conceito de ajuste ao/à interlocutor/a, cunhado em língua inglesa como recipient design (SACKS et al., 1974), que buscamos nos alistar ao debate proposto neste número especial da Revista da ANPOLL. Como o objeto central de investigação da Análise da Conversa, doravante AC, é a fala-em-interação (sendo que interação é aqui entendida em suas múltiplas formas semióticas de materialização), partimos de um entendimento de letramento não limitado à modalidade escrita e adotamos a perspectiva dos Novos Estudos do Letramento, doravante NLS ${ }^{7}$. Segundo Street (2014 [1995]), "o letramento se relaciona tanto com o discurso oral quanto com práticas materiais específicas com as quais ele se entrelaça e se define" (STREET, 2014, p. 138). As pesquisas desse autor, à semelhança do que é feito em AC, procuram "mover o estudo do letramento para longe de generalizações idealizadas sobre a natureza da Linguagem (...) na direção de entendimentos mais concretos (...) em contextos sociais 'reais"' (STREET, 2014, p. 19). É exatamente nesse ponto que os NLS se entrecruzam com a AC, tornando as fronteiras disciplinares mais fluidas e dinâmicas.

Nas seções seguintes, buscamos elucidar ainda mais esse entrecruzamento, seja por meio de uma reflexão que aborda a natureza social e multirreferencial do letramento, seja por meio de uma discussão baseada na análise de dados de fala-em-interação gerados em contextos de produção natural de linguagem. Queremos, por meio das análises apresentadas, argumentar que a granularidade do olhar investigativo da AC oportuniza uma demonstração empiricamente situada de diversidade cultural, statuses (epistêmicos e sociais), legitimidade, episteme, entre outros, e que os interagentes, se orientam (de forma demonstrável) a essas identidades e contextos locais e situados. Em outras palavras, a relação entre letramento e AC não precisa ser forjada. Ela já existe. É orgânica e transversal.

\section{NOVOS ESTUDOS DO LETRAMENTO ${ }^{8}$ E ANÁLISE DA CONVERSA: ALGUNS ENTRECRUZAMENTOS}

Kleiman (2010, p. 389) posiciona letramento como um conjunto de "práticas legitimadas globalmente" que contribuem para construir identidades, sob o conceito de "letramentos locais". Nesse sentido, tais práticas, que "fornecem orientações momentâneas, locais, circunstanciais, passo a passo, sobre o status, poder e legitimidade dos participantes da interação" (KLEIMAN, loc. cit.) já apontam uma importante relação com a AC, cuja prioridade de investigação reside em observar densamente "o que as pessoas estão fazendo, como elas entendem o que as outras pessoas estão fazendo, enfim, que se olhe para as pequenas ações das pessoas a partir da perspectiva do próprio local onde isso tudo está acontecendo." (OSTERMANN, 2012, p. 35).

A preferência pelo termo "letramentos" (no plural) remonta a uma diversidade de práticas em detrimento de sua forma singular, considerada monolítica (STREET, 2014 [1995]), e permite interpretar que o próprio entendimento de letramento é sensível ao "contexto social" (STREET, op. cit., p. 176), uma vez que esse conceito se ancora em "parâmetros mais amplos", e uma possível análise da relação entre oralidade e letramento exigiria essa concepção. Do mesmo modo, o entendimento de que a conversa é sensível ao contexto e às práticas situadas está intrinsecamente ligado ao princípio da AC que permeia nossa argumentação: "o ajuste ao interlocutor". Considerado por Sacks et al. (2003 [1974], p. 51) "o princípio mais geral que

\footnotetext{
${ }^{7}$ Optamos por manter a sigla do termo em inglês - NLS (cf. STREET, 2003) - em vez de transformá-la em "NEL", pois parece ainda não haver consenso sobre seu uso na literatura em língua portuguesa.
} 
particulariza as interações conversacionais", é por meio do recurso de ajuste ao interlocutor que os interagentes selecionam palavras, propõem tópicos de discussão, ordenam as sequências interacionais (tanto em relação ao formato ${ }^{9}$ quanto ao tamanho dos turnos), além de delimitar o início e o fim das conversas (e.g. PILLET-SHORE, 2012; DEPPERMANN; DE STEFANI, 2019).

Entendemos, assim, que, na comunicação médico-paciente, é a partir de uma perspectiva em que interagentes são expostos/as ao uso de uma multiplicidade de recursos, "feitos sob medida" para cada interlocutor/a e para cada situação interacional, que se propicia a construção de sentido que é imperativa para a autonomia da paciente na tomada de decisão sobre sua vida. Nesse sentido, NLS e AC também se entrecruzam, quando compreendem a língua como ação social, ou seja, como

\begin{abstract}
situada no espaço/tempo e de natureza relacional (...) presente também nas ações sociointeracionais do cotidiano, na medida em que os interactantes assumem a responsabilidade de sinalizar como devem ser interpretadas as formas que produzem e também como estão interpretando/avaliando as produzidas por outrem. (SIGNORINI, 2008, p. 121)
\end{abstract}

Essa explicação, na verdade, nos remete a outro conceito se faz relevante aqui: o de "letramento em saúde" (originalmente, Health Literacy). O entendimento de ação social, como posto por Signorini (2008) e que argumentamos ser compartilhado entre a AC e os NLS, converge com os estudos sobre "letramento em saúde", que é definido como "o grau pelo qual os indivíduos têm a capacidade para obter, processar e entender informações básicas e serviços necessários para a tomada de decisões adequadas em saúde" (RATZAN; PARKER, 2000, p. vi). Isso se materializa na proporção em que, a cada interação realizada entre profissionais e usuários de um sistema de saúde, variados recursos são mobilizados na produção conjunta de sentidos sobre os procedimentos tornados relevantes, seja para a realização de um exame ou ministração de medicamentos, seja para uma tomada de decisão.

Rebecca Sudore e Dean Schillinger (2009) asseveram que, justamente em função de o baixo letramento em saúde estar associado a resultados negativos no que tange a inequidades sociais e cuidados em saúde, faz-se imperativo que sejam adotadas melhores práticas na interação médico-paciente, como, por exemplo, com uma "comunicação centrada no/a paciente, [e com] técnicas claras de comunicação e métodos de ensino com metas" (SUDORE; SCHILLINGER, 2009, p. 20). Ainda, que somente com a adoção dessas e outras práticas, os desfechos em cuidados de saúde para pacientes com baixo letramento podem ser melhorados e a inequidade, diminuída.

A preocupação com letramento em saúde assume tamanha importância que, em países como os EUA, o seu próprio Ministério da Saúde produziu um guia destinado a profissionais da saúde sobre como promover o letramento em saúde (U.S. DEPARTMENT OF HEALTH AND HUMAN SERVICES, s.d.). Além disso, há larga disseminação desses estudos para além da academia, entre o público leigo, apontando justamente para questões da ordem interacional. No encarte sobre saúde do New York Times (2009), no texto "Você sabe o que seu médico está falando?", Pauline Chen chama a atenção para as dificuldades que cidadãos/cidadãs comuns apresentam no que tange à obtenção e compreensão de informações sobre saúde e sobre ações e tomadas de decisão imperativas em cuidados à saúde.

É a partir desse cenário de interlocução que esmiuçamos a seguir, empiricamente, a relação que enxergamos entre as preocupações dos NLS, da AC e do Letramento em Saúde. Assim, apresentamos, a seguir, análises de dados em português brasileiro em que os

\footnotetext{
${ }^{9}$ Formato é entendido aqui como design de uma ação, envolvendo a seleção de recursos de diferentes campos semióticos, verbais (lexicais, sintáticos, prosódicos) e não verbais.
} 
interagentes se encontram em consultas de aconselhamento genético e estão envolvidos em práticas que estamos considerando como "práticas de letramento em saúde" e repercutem em tomadas de decisão. As análises contemplam, então, os letramentos como pervasivos ao mesmo tempo em que os fenômenos interacionais, caros à $\mathrm{AC}$, se tornam relevantes na perspectiva dos participantes.

\section{DE CÉLULAS COMO "TIJOLINHOS" A "TRISSOMIA DO ONZE": OS DIFERENTES RECURSOS MOBILIZADOS EM PRÁTICAS DE LETRAMENTO EM SAÚDE COM VISTAS AO AJUSTE AO INTERLOCUTOR}

Os dados que embasam nossa argumentação, em especial, sobre a relação com o princípio de ajuste ao/à interlocutor/a, foram gerados entre 2013 e 2014 em um hospital credenciado ao Sistema Único de Saúde (SUS); mais especificamente, no setor especializado em gestações de médio e alto risco, e que frequentemente lida com anomalias fetais. Os dois excertos analisados advêm de consultas realizadas com um médico geneticista (chamado aqui de Jeferson) que se destaca por sua habilidade em fazer ajustes a diferentes interlocutoras, levando em conta suas diversidades linguística, educacional, econômica, cultural e de acesso epistêmico. Uma vez que os interagentes demonstram estar associados a contextos sociais e culturais distintos e que a intersubjetividade precisa ser garantida, as ações de Jeferson são caracteristicamente voltadas para a missão de assegurar que suas pacientes tomem decisões de forma autônoma e informada. Nesse sentido, Jeferson, então, lança mão de práticas de letramento em saúde. ${ }^{10}$

No Excerto 2, além de Jeferson (MÉD), estão presentes a gestante Ana (PAC) (27 semanas de gestação) e seu marido (ACO). O contexto em que essa interação se dá é crucial para que se compreendam as consequências dessa consulta de aconselhamento genético. A ecografia fetal anterior revelara cistos nos pulmões do feto, e a consulta marcada com Jeferson envolve o aconselhamento para a realização do exame de cariótipo fetal com fins de investigação de possível associação dos cistos com alguma síndrome. O momento explorado aqui refere-se à explicação sobre a amniocentese, um procedimento invasivo que demanda punção do abdômen materno para extração de líquido amniótico e posterior avaliação genética fetal - e que pode, ainda que raramente, causar abortamento espontâneo.

\footnotetext{
${ }^{10}$ Para maior aprofundamento da distinção entre eventos e práticas de letramento, sugerimos Street (2003). Como estamos amparados por Street (2014[1995]) segundo o qual os letramentos não só dizem respeito a práticas relativas à escrita, mas também à oralidade, estamos, portanto, considerando que, independentemente dessa distinção, os recursos mobilizados oralmente pelos participantes servem de base para que os diferentes backgrounds sociais dos interagentes emerjam na interação e se constituam como um contexto de letramento.
} 
Excerto 2: “Tipo aqueles tijolinhos” (HMF_ACONGEN_ana_JEFERSON_15_10_13)

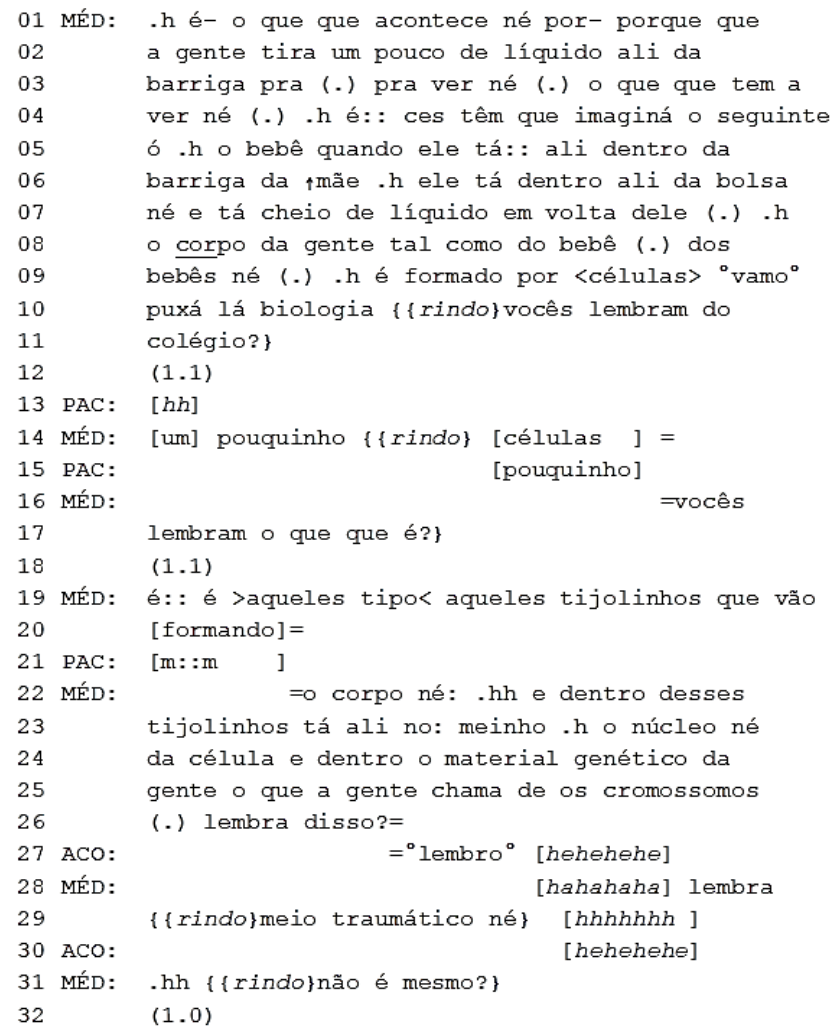

Nas linhas 1-12, à medida que o médico avança na explicação do procedimento da amniocentese, percebem-se cortes no fluxo interacional. $\mathrm{O}$ primeiro deles acontece depois de uma hesitação ("é: :", linha 4), quando ele inicia uma nova ação, convidando a gestante e acompanhante a fazer uma representação mental ("ces têm que imaginá o seguinte ó", linhas 4-5). Com essa ação, ele suspende a explicação em andamento (sobre o procedimento de punção e a retirada de líquido amniótico) e inicia outra, em que descreve como o feto está disposto no útero materno ("ele tá dentro ali da bolsa né e tá cheio de líquido em volta dele", linhas 6-7). Assim que acontece essa descrição, ocorre nova interrupção do fluxo para outra explicação ("O corpo da gente tal como do bebê (.) dos bebês né (.) .h é formado por <células>", linhas 8-9).

Em outras palavras, à medida que vai inserindo novos elementos de explicação, o médico Jeferson também vai (re)calibrando sua fala e ações produzidas por meio dela. Desse modo, ao fornecer novas explicações, ele ajusta suas ações para produzir, em conjunto com a paciente e acompanhante, um entendimento compartilhado sobre a amniocentese. Sublinhamos aqui a importância de se assegurar o entendimento compartilhado nesse caso, já que a decisão pela realização (ou não) do procedimento deve ser feita de forma autônoma e informada pela paciente.

Quando se refere a células (nas linhas 8-9), Jeferson suspende mais uma vez o fluxo de sua explicação para fazer mais uma "calibragem" situada de sua fala: "vamo o puxá lá biologia \{ rindo\}vocês lembram do colégio?\}", linhas 9-11). Ao fazer esse convite (i.e. para se lembrarem das aulas de biologia), seguido de uma pergunta (i.e. se os interlocutores se lembram de tratar disso nos tempos de escola), ele traz à interação um contexto sócio-histórico típico de eventos de letramento (i.e. escola) e oportuniza a (re)contextualização de conhecimentos tipicamente lá constituídos - uma espécie de "metaletramento". 
Atente-se ainda para o fato de que quando se refere a "células", o médico não apenas se orienta para demonstrações não verbais dos participantes, mas também requer uma confirmação por meio de uma pergunta ("\{\{rindo\}vocês lembram do colégio?\}", linhas 10-11). Ao produzir essa pergunta esboçando um sorriso ${ }^{11}$, o médico se orienta para o fato de que não há uma expectativa de que a paciente e acompanhante tenham que saber do que se constitui uma célula. Contudo, Jeferson precisa assegurar entendimento de célula para chegar à explicação de DNA).

É possível observar aqui, e nos turnos seguintes, que o profissional trabalha ativamente no processo de referenciação compartilhada com seus interlocutores para, a partir desse compartilhamento, avançar na explicação. Essa busca da referenciação compartilhada é realizada com vários índices de atenuação, já que a ação de reconhecer que não se sabe algo é uma ação despreferida ${ }^{12}$.

Uma vez que os potenciais respondentes se orientam para não tomar o turno (e.g.. silêncio, linha 12, e expiração audível da paciente, linha 13), é importante destacar que, se nada fosse feito pelo médico, tal lacuna poderia gerar certo constrangimento. Entretanto, a retomada do turno por Jeferson, oferecendo uma resposta candidata (“[um] pouquinho", 1. 14) ao seu próprio pedido de informação, parece ser interpretada pela paciente Ana e seu companheiro como uma iniciativa de amenização de algum potencial constrangimento, já que a paciente, ao repetir parcialmente o turno do médico (" [pouquinho]", linha 15), aceita como adequada essa interpretação. Enquanto isso, em sobreposição, o médico reformula a pergunta ("células vocês lembram o que que é?", 1.14 e linhas 16-17) com a mesma orientação amenizadora, haja vista a repetição do método "fala risada", como fizera anteriormente.

A fim de ilustrar a trajetória interacional que o profissional trilha para reajustar suas ações, orientado para as reações de seus interlocutores e num processo ativo de garantir que eles compreendam o procedimento da amniocentese (i.e. o qual deverão decidir informada e autonomamente se desejam fazer), apresentamos a imagem a seguir:

Figura 3: Trajetória interacional das explicações de Jeferson

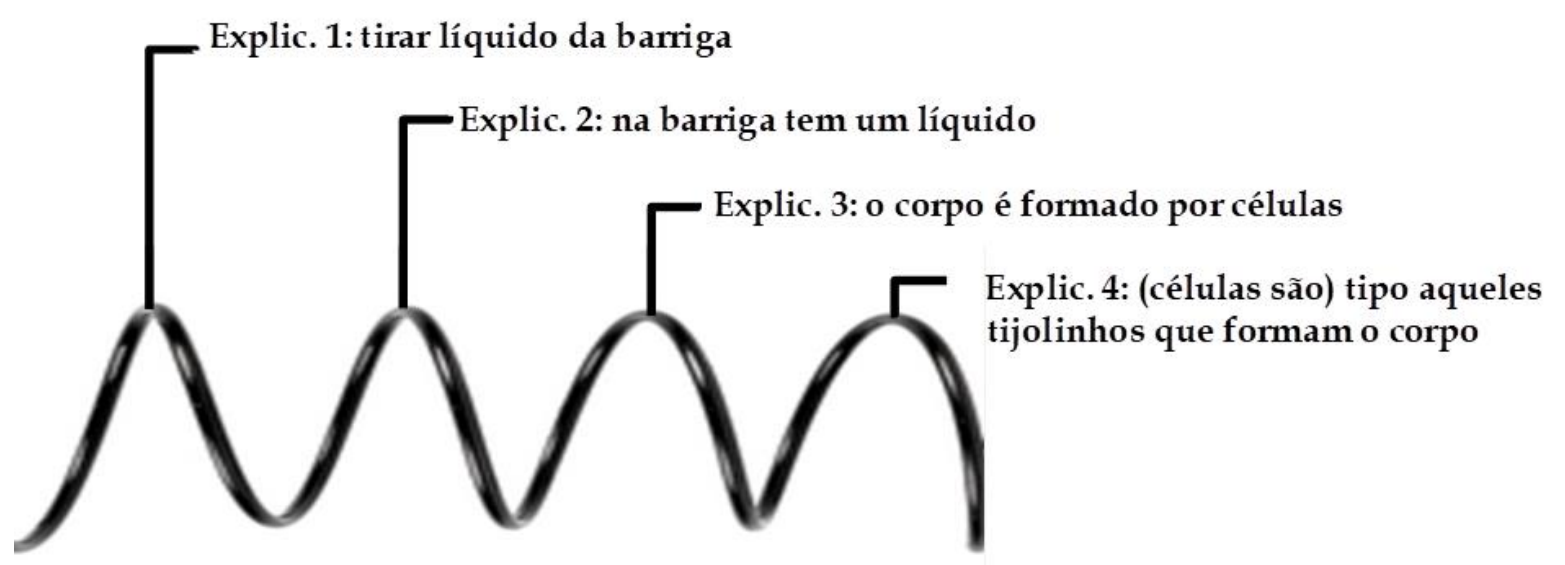

Fonte: Os autores.

O fluxo conversacional da interação, cujo percurso é representado na Fig. 3, é possivelmente afetado pelas (re)orientações e ajustes dos participantes para a inteligibilidade

\footnotetext{
11 Trata-se de uma prática interacional que referenciamos pela expressão "fala risada" em uma tentativa de tradução para "smiley voice", termo usado na literatura da AC em língua inglesa.

${ }^{12}$ Ações preferidas são aquelas que têm seu formato de produção alinhado com a ação anterior e se implementam, por exemplo, sem atrasos ou hesitações. Ações despreferidas, por sua vez, são normalmente produzidas com atrasos e hesitações em resposta à ação anterior. Sobre ações (des)preferidas, ver Pomerantz (1984).
} 
do que está sendo tratado. Diferentemente do que se poderia apressadamente supor, os turnos de fala em geral não se configuram em "linha reta", mas em espirais, cujas "voltas" vão se amoldando conforme as demonstrações dos participantes sobre o que se deveria retomar em prol do ajuste ao interlocutor, a quanto sabe e a quanto precisa saber para tomar uma decisão sobre o procedimento. Nesse caso, na ação de explicar o procedimento, o médico se orienta para fazer referências a um conhecimento comum entre ele e seus interlocutores. Para fazer essas referências, o fluxo da informação é suspenso em função de remissão a algum referente "anterior". Ao glosarmos analiticamente essas multirreferencialidades, conseguimos, portanto, mostrar como práticas de letramento em saúde se realizam local e situadamente na práxis interacional, ajustando-se aos contextos que são (re)constituídos e revelados a cada novo turno de fala. A consequência dessa explicação "feita sob medida" para esses interlocutores é justamente a demonstração deles de que compreenderam, portanto, como se daria o procedimento.

Vejamos agora o Excerto 3, envolvendo outra paciente, Tatiane (PAC), que não é gestante, mas que consulta o médico Jeferson em consequência de diagnóstico de abortamento recorrente. Essa consulta, assim, como a anterior, apresenta relevância para a paciente no que tange a uma importante tomada de decisão: a de gerar ou não uma nova vida frente ao seu histórico de perdas gestacionais. É importante destacar que Tatiane é médica e que Jeferson tem acesso a essa informação antes mesmo de a consulta iniciar.

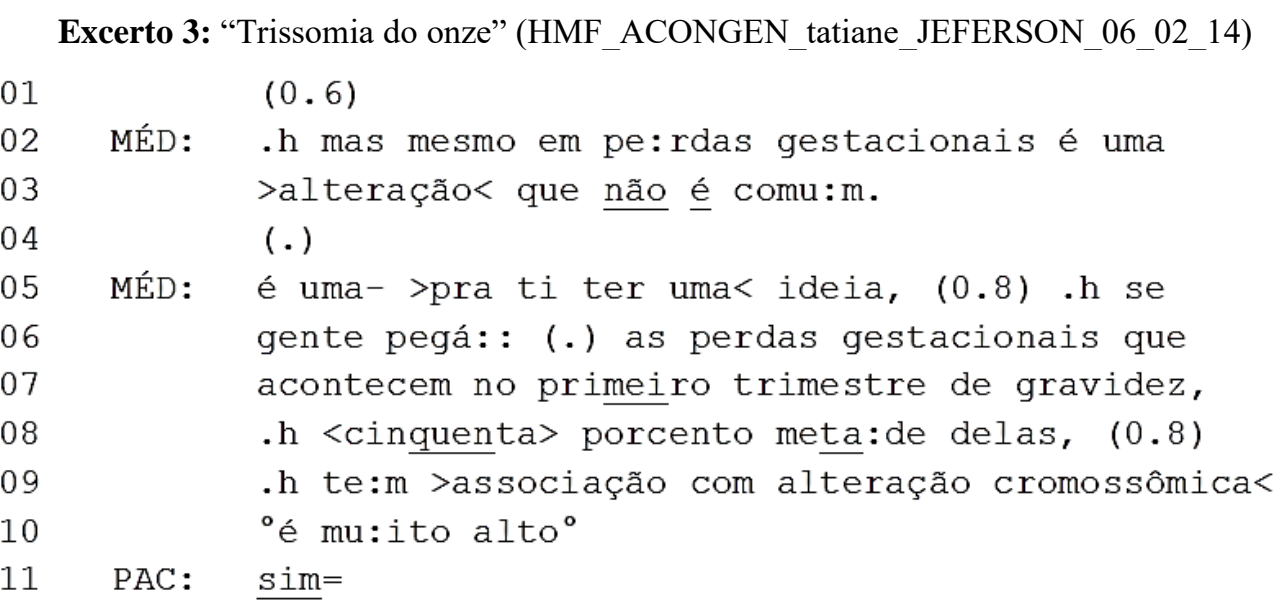

Fonte: Os autores

Nessa interação, em que a paciente busca causas para os abortamentos que sofreu, Jeferson utiliza léxico técnico e não metafórico. A utilização de expressões como "alteração cromossômica" (linha 9) e dados estatísticos e relacionais ("<cinquenta> porcento meta: de delas, (0.8).h te:m >associação com alteração cromossômica< "é mu:ito alto o", linhas 8-10) também evidenciam ajuste à interlocutora.

Até a linha 11, para além da resposta mínima (“sim", linha 11), ainda não há indícios de compreensão de Tatiane sobre o que Jeferson explica de forma técnica. No entanto, na continuidade da interação, observam-se evidências de que médico e paciente estão em compreensão mútua. 
Excerto 4: "Trissomia do onze" (continuação do excerto anterior)

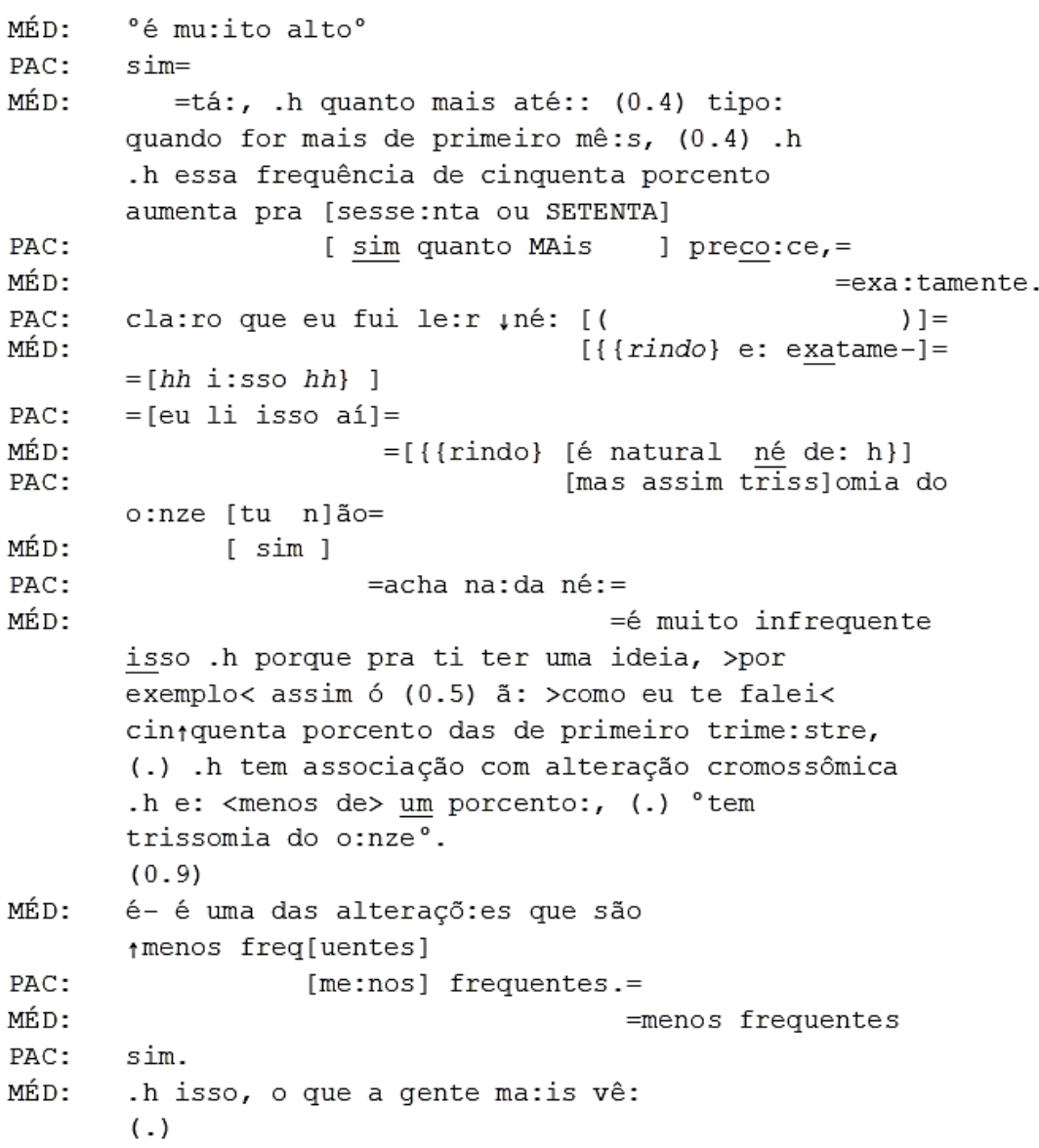

Fonte: Os autores

Como se vê, reiteradamente, há remissões a dados estatísticos. À medida que os dados são informados, a compreensão vai se constituindo conjuntamente entre os participantes, com crescente participação da paciente. Se considerarmos os três longos turnos do geneticista (linhas 5-10, 12-15 e 27-33), percebemos uma hierarquização das informações em "graus" de especificidade.

Figura 4: Perdas gestacionais/Trissomia do 11

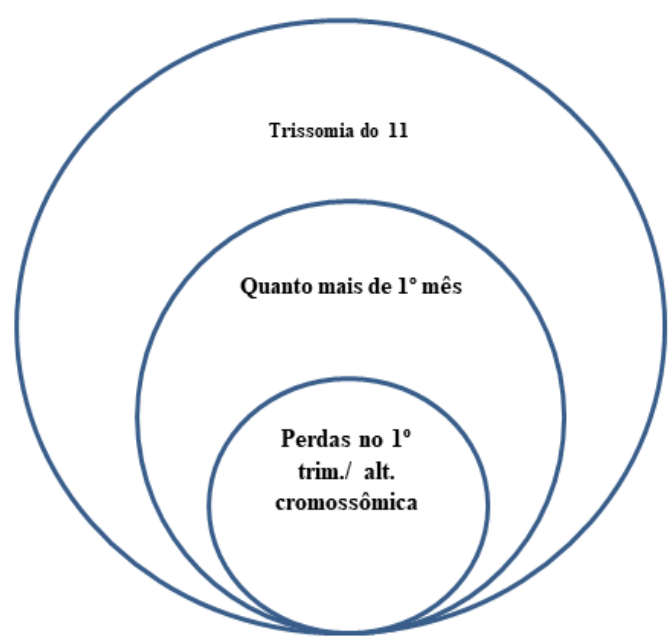

Fonte: Os autores. 
Como mostra a Fig. 4, conforme a interação avança, o médico apresenta informações cada vez mais específicas, mas não sem certa calibragem e "autorização" da interlocutora. $\mathrm{O}$ movimento crescente de especificidade resulta de uma demanda da interlocutora, que se apresenta como tendo acesso epistêmico a essas especificidades, como observado na reformulação que ela produz "[sim quanto MAis] preco:ce,", linha 16). Adicionalmente, a paciente presta contas sobre sua ação anterior (“cla:ro que eu fui le:r $\downarrow$ né:", linha 18), apresentando-se, assim, mais uma vez, com letramento na área, bem como com autonomia para buscar conhecimento mais específico. Aliás, faz-se importante registrar aqui que, no que tange especificamente a letramento em saúde, a autonomia para navegar em diferentes fontes de conhecimento é uma das características principais que se deseja de um cidadão (SORENSEN et al., 2012). A prestação de contas de Tatiane, a propósito, é naturalizada por Jeferson (“[ $\{\{$ rindo $\}$ [é natural né de: $\mathrm{h}\}]$ ”, linha 22).

Esse afunilamento caracteriza o formato de como o médico provê informações. Como a paciente já chega ao consultório sabendo que uma de suas gestações anteriores revelara "trissomia do 11", a ação que ela torna relevante, na sequência, configura sua demanda por saber sobre a frequência dessa alteração cromossômica, ao que Jeferson atende (linhas 27-33).

Assim como fizera com a gestante Ana e seu acompanhante, o médico, nessa consulta, também parte da busca da referenciação demonstradamente compartilhada com a interlocutora, para, apenas então, prosseguir na produção conjunta de um diagnóstico. A diferença entre os dois atendimentos está nos métodos usados para prover explicações/informações aos/às interlocutores/as e em como esses métodos são localmente situados e ajustados aos/às diferentes interlocutores/as e aos seus saberes situados.

\section{FALAS "SOB MEDIDA": O TRANSBORDAMENTO DE LETRAMENTO NA FALA-EM-INTERAÇÃO}

A análise interacional apresentada neste artigo evidencia as práticas de um médico com status epistêmico em sua área de especialidade - Genética - que se apresenta também como com larga competência interacional ao oportunizar momentos de genuína construção compartilhada de sentido acerca de informações técnico-científicas cruciais para as tomadas de decisão das pacientes. Como se viu, o profissional lança mão de diferentes recursos como contextos para ajustar suas ações interacionais (no sentido de design) a cada interlocutora e a cada novo turno sequencial. A análise do turno a turno das consultas torna visível a constelação de recursos acionados pelo geneticista na construção de sentido compartilhado, como o uso de metáforas, léxico leigo, autorreparos e prosódia.

Na relação instituída entre o médico e a paciente apresentada na abertura deste artigo (Interação 1), a diferença dos statuses epistêmicos entre os participantes fica marcada. Como a identidade como linguista é trazida pela paciente à interação e, assim, acionada como localmente relevante, fica evidente que, mesmo tendo ela fornecido um contexto de interpretação (“Ah, sim. Eu sei. Eu sou linguista.”, linha 7) que poderia dispensar as explicações morfológicas em curso, o que ocorre é, ao contrário, a continuação da "aula". Desse modo, destacam-se, a reboque, os diferentes statuses sociais na interação: ela, uma paciente necessitando de atendimento médico; ele, um médico, detentor de saberes médicos e não médicos (i.e. prefixos) e, principalmente, um provedor de cuidados.

Por outro lado, nas consultas genéticas, o profissional se mostra atento e em contínua (re)orientação às circunstâncias localmente situadas de cada interação e de cada interagente, não recorrendo a mecanismos de intimidação para se afirmar como autoridade constituída ou tomando como pressuposto que tudo o que diz é entendido pelo/a interlocutor/a. Assim como o médico da Interação 1, Jeferson é, do ponto de vista profissional, um provedor de cuidados 
de igual modo, mas, diferentemente daquele, a distinção de "saberes" entre ele e suas pacientes se evidencia, não pela imposição de um saber, mas pelo trabalho interacional que faz no compartilhamento de saberes. E, mais importante: possíveis distinções entre os statuses (epistêmicos e sociais) se revelam no modo como se faz esse compartilhamento.

Contudo, a negociação e a legitimação das posições (epistêmicas: "quem sabe", "quem não sabe" e "o quê (não) sabe"; sociais: médico e paciente), que podem até ter sido estabelecidas a priori, só vão se materializar (ou não) interacionalmente. Por essa razão, se estamos tratando de Novos Estudos de Letramento e de Letramento em Saúde, estamos admitindo que a condução das práticas implementadas em atendimentos de atenção à saúde devem se aprofundar para níveis menos superficiais do que ingenuamente compreender que o geneticista esteja, por suposto, tratando a paciente Ana e seu marido com condescendência ou que esteja privilegiando a paciente Tatiane com informações técnicas por ela ser médica como ele.

A partir de uma visão analítica contextualmente aprofundada, baseada nas importantes minúcias que encampam a compreensão do todo interacional, não é difícil entender que os conceitos de letramentos são pervasivos e que podem ser apreciados pela AC na medida em que as práticas locais e situadas engendradas por Jeferson não são meras ferramentas para análise, mas são a própria glosa da negociação local de sentidos realizada pelos participantes das interações.

Sendo assim, buscamos, com este artigo, também discutir como diferentes práticas são constituídas, não para excluir ou marcar diferenças, mas para, ao contrário, incluir e promover a socialização do conhecimento e a autonomia informada de decisão entre os pacientes, possibilitando assim, que tomem decisões importantes sobre sua saúde e, consequentemente, sobre suas vidas. Nesse sentido, podemos afirmar que a AC consegue explicitar, no cerne das trocas de turnos e das orientações dos interagentes, uma concepção tão amplamente tratada no senso comum - a de empoderamento social - em cenários também tão importantes, como o dos atendimentos em saúde. Observe-se que em vários países, não apenas o conceito de "Letramento em Saúde" já é largamente difundido, como também fomentado por meio de diretrizes governamentais e de incentivo à pesquisa (e.g. U.S. DEPARTMENT OF HEALTH AND HUMAN SERVICES, s.d.), bem como por meio de instituições profissionais (e.g. NIELSEN-BOHLMAN et al., 2004). Num país de tamanha diversidade social, linguística, cultural e de letramento como o Brasil, os Novos Estudos do Letramento certamente muito têm a contribuir também para a saúde; e os estudos da Análise da Conversa, que olham justamente para as práticas interacionais situadas - ousamos asseverar - também.

\section{Referências}

DEPPERMANN, Arnulf; DE STEFANI, Elwys. Defining in talk-in-interaction: Recipientdesign through negative definitional components. Journal of Pragmatics, [S.L]. v. 140, p.140$155,2019$.

DREW, Paul; WALKER, Traci; OGDEN, Richard. "Self-repair and action construction". In: HAYASHI, Makato; RAYMOND, Geoff; SIDNELL, Jack (Eds.). Conversational Repair and Human Understanding. Cambridge University Press, p.71-94, 2013.

JEFFERSON, Gail. "Transcription notation". In: ATKINSON, J. Maxwell; HERITAGE, John. (Eds.). Structures of social action. New York: Cambridge University Press, p. ix-xvi, 1984. 
KLEIMAN, Angela. Trajetórias de acesso ao mundo da escrita: relevância das práticas não escolares de letramento para o letramento escolar. Perspectiva, [S.L]. v. 28, n. 2, 375-400, 2010.

NEW YORK TIMES. Do you understand what your doctor is saying?. 2009, Apr 2. https://www.nytimes.com/2009/04/02/health/02chen.html

NIELSEN-BOHLMAN, L; PANZER, Allison; KINDIG, David. Health Literacy: A Prescription to End Confusion. Washington: National Academy of Science, 2004.

OSTERMANN, Ana C. "Análise da conversa: o estudo da fala-em-interação". In: OSTERMANN, Ana C.; MENEGHEL, Stela (Orgs.). Humanização. Gênero. Poder: contribuições dos estudos de fala-em-interação para a atenção à saúde. Campinas: Mercado de Letras; Rio de Janeiro: Editora Fiocruz, p. 33-43, 2012.

PILLET-SHORE, Danielle. Greeting: Displaying Stance Through Prosodic Recipient Design. Research on Language \& Social Interaction, [S.L]. v. 45, n. 4, p. 375-398, 2012.

POMERANTZ, Anita. "Agreeing and disagreeing with assessments: some features of preferred/dispreferred turn shapes". In: POMERANTZ, Anita. Structures of social action. New York: Cambridge University Press, p. 57-101, 1984.

RATZAN, Scott; PARKER Ruth. National Library of Medicine Current Bibliographies in Medicine: Health Literacy. Bethesda, MD: National Institutes of Health, U.S. Department of Health and Human Services, 2000.

SACKS, Harvey; SCHEGLOFF, Emanuel; JEFFERSON, Gail. Sistemática elementar para a organização da tomada de turnos para a conversa. Veredas, Juiz de Fora, v. 7, n. 1, p. 9-73, 2003 [1974].

SCHEGLOFF, Emanuel; SACKS, Harvey; JEFFERSON, Gail. The preference for selfcorrection in the organization of repair in conversation. Language, 53, p. 361-382, 1977.

SORENSEN, Kristine; VAN DEN BROUCKE, Stephan; FULLAM, James; DOYLE, Gerardine PELIKAN, Jurgen; SLONSKA, Zofia; BRAND, Helmut. Health literacy and public health: A systematic review and integration of definitions and models. BMC Public Health. [S.L]. 2012, 12: 80.2012, 12: 80. Disponível em: https://www.ncbi.nlm.nih.gov/pmc/articles/PMC3292515

SOUZA, Juliane; PINHO, Maria. Interdisciplinaridade e transdisciplinaridade como fundamentos na ação pedagógica: aproximações teórico-conceituais. Signos, [S.L]; v. 38, n. 2, p. 93-110, 2017. 
STIVERS, Tanya; MONDADA, Lorenza; STEENSIG, Jackob. The Morality of Knowledge in Conversation. Cambridge: Cambridge University Press. 2011.

STREET, Brian. Letramentos Sociais: abordagens críticas do letramento no desenvolvimento, na etnografia e na educação. São Paulo: Parábola Editorial. 2014 [1995].

STREET, Brian. What's "new" in New Literacy Studies? Critical approaches to literacy in theory and practice. Current Issues in Comparative Education, [S.L]. v. 5, n. 2, p. 77-91, 2003.

SUDORE, Rebecca; SCHILLINGER, Dean. Interventions to Improve Care for Patients with Limited Health Literacy. J Clin Outcomes Manag., [S.L]. v. 16, n.1. p. 20-29, 2009.

U.S. DEPARTMENT OF HEALTH AND HUMAN SERVICES. Grants and Funding: Extramural Programs (EP). Washington: National Institutes of Health (NIH). Disponível em: https://www.nlm.nih.gov/ep/healthlit.html

U.S. DEPARTMENT OF HEALTH AND HUMAN SERVICES. Quick Guide to Health Literacy. Washington: Office of Disease Prevention and Health Promotions. s.d. Disponível em: https://health.gov/communication/literacy/quickguide/quickguide.pdf 


\section{Anexos}

ANEXO: Convenções de transcrição ${ }^{13}$

[texto]

$=$

(1.8)

(.)

,

$?$

$>$ textor

<texto>

${ }^{\circ}$ texto ${ }^{\circ}$

TEXTO

Texto

(texto)

$(\quad)$

( (texto) )

$\downarrow$

$\uparrow$

hhh

. hhh

$\{\{$ rindo $\}$
Falas sobrepostas

Fala contígua

Indicação temporal de silêncio em segundos

Indicação temporal de silêncio com menos de 0.2 segundos.

Entonação contínua

Entonação descendente

Entonação ascendente

Interrupção abrupta da fala

Alongamento de som

Fala mais rápida

Fala mais lenta

Fala com volume mais baixo

Fala com volume mais alto

Sílaba, palavra ou som acentuado

Dúvidas na transcrição

Texto inaudível

Comentários do/a transcritor/a

Alteração de timbre para b aixo (grave)

Alteração de timbre para cima (agudo)

Expiração audível

Inspir ação audível

\} Trecho produzido com fala risada
Ana Cristina Ostermann aco@unisinos.br

Roberto Perobelli robertoperobelli@gmail.com

Recebido em: 07 de Julho de 2019 Aceito em: 18 de Agosto de 2019

Publicado em: Setembro de 2019

${ }^{13}$ Quadro baseado nas convenções propostas por Jefferson (1984). 